Quarterly Journal of Economics and Economic Policy

2014 VOLUME 9 ISSUE 2, June

p-ISSN 1689-765X, e-ISSN 2353-3293

www.economic-policy.pl

Ciborowski R. (2014), Innovation Process Adjusting in Peripheral Regions. The Case of Podlaskie Voivodship, "Equilibrium. Quarterly Journal of Economics and Economic Policy", Volume 9, Issue 2, pp. 57-72, DOI: http://dx.doi.org/10.12775/EQUIL.2014.011

Robert Ciborowski ${ }^{*}$

University of Bialystok, Poland

\title{
Innovation Process Adjusting in Peripheral Regions. The Case of Podlaskie Voivodship
}

\section{JEL Classification: $O 30$}

Keywords: innovation system, peripheral region, innovation

\begin{abstract}
Comparative studies indicate that innovation activity in Poland is, in general, significantly below that of EU and in North-east it is below that of other parts of Poland. There is peripheral region with traditional structure of production and employment.

The North-east remains one of the least innovative regions of Poland and enlarged EU. This is probably the result of the obsolete institutional setting, which doesn't reflect the requirements of modern international competitiveness. It is the heritage of past times, where creation of the innovation system wasn't considered a priority factor of economic development. Additionally, Poland is still undergoing intensive modernization of its technology capabilities. The capital and production structure are way outdated and don't meet the demands of the international trade competition, most of all the non-price competition.

That is why it seems that creating conditions for innovation system might become a crucial factors determining the nature and dynamics of development processes as well as influencing the North-east future innovation capability. Creating a new regional innovation structure and transfer of technologies should support modernization processes in companies and the creation of development opportunities for the national economy as a whole and especially in peripheral regions. Those processes will accelerate technological convergence of regions and the economy.
\end{abstract}

(c) Copyright Institute of Economic Research \& Polish Economic Society Branch in Toruń Date of submission: April 14, 2013; date of acceptance: November 13, 2013

* Contact: r.ciborowski@uwb.edu.pl, University of Bialystok, ul. Warszawska 63, 15-062 Białystok, Poland 
The main aim of the article is an analysis of innovation system functioning and institutional support in this process in North-east Poland.

\section{Introduction}

In order to determine what institutional factors affect innovation, it is necessary to define the categories of social institutions and to describe the mechanism of their impact on the economy. What seems to be among the most significant elements of an institutional network is an innovation system which makes it possible to select such stimuli that contribute to better skill-building and increase a society's knowledge (North, 1997, p.7). In this way, institutions can have an influence on the structure production factors, accumulation of knowledge and capital, techniques, technology, efficiency, technological progress, and the organisation of production processes.

A system of innovation can, therefore, be regarded as an institution which boosts innovation and shapes its nature. It includes the following constituent parts: science and technology system, education, research and development, and innovation policies. These have to be effectively supported by economic policy instruments whose efficiency directly translates into the performance of a particular innovation system.

The purpose of this paper is to analyse the growth capabilities of innovation in Podlaskie Voivodeship as a peripheral region, with special attention to its innovation system.

This article reports the estimates of the long-run effects of regional development in the scope of innovation. It also describes how shifts in firms activity required innovation and how technological changes influenced the region.

\section{Conditions for creating innovation systems and their impact on innovation processes}

Analysis of individual regions reveals that each of them follows a different, unique innovation path. This also means that particular regions face diverse conditions in which their innovation systems function, which has a bearing on the transformation on entire economic systems and their competitive position. The processes of globalisation and integration have also led to a considerable diversity of external conditions, resulting in greater internationalisation of innovation systems and creation of technological systems ${ }^{1}$.

${ }^{1}$ Technological system - a group of institutions which support and implement innovation; the network of interactions among these within particular technologies. 
The differences between innovation systems are caused by their environment to a greater extent than by external factors. Consolidation and development of innovation are impossible without political and economic stability or openness of markets. Nevertheless, under the circumstances of globalisation, it is difficult to assess what elements of innovation systems have the highest chance of survival and growth. This usually depends on the participants of those systems (enterprises), their innovation performance, technology transfer, as well as on their future competitive position in international markets.

Technology transfer plays a major role here because its tools are an integral part of innovation change. They should be stable, complex (support for innovation cannot happen independently of support for technology transfer) and co-ordinated, since institutions should participate in the creation and diffusion of technical innovation and must closely co-operate, with one institution as the co-ordinator of the entire process. Taking the above into consideration, one can distinguish two strictly interrelated processes that determine the efficiency of innovation systems:

- development of enterprise sector and market environment; their influence on the innovation capacity of companies and technological infrastructure;

- transfer of technology and its role in creating efficient management structures capable of enhancing internal and external competitiveness and cooperation.

When analysing these processes, one must take into account the interdependencies between the spheres of science, technology and entrepreneurship, as well as their institutional and macroeconomic aspects. It is institutions that make it possible to monitor business environment and to introduce changes in the way business entities operate. What is more, they play a crucial role in determining the competitive ability of companies and the pace of economic development.

In order to specify the structural and institutional conditions for the creation of innovation systems, it is necessary do conduct an in-depth analysis of national and regional innovation systems. A comparison of these systems in highly developed countries makes it possible to establish the structure and significance of institutional segments, which include:

- companies and their innovation capacities, including their vertical relationships with suppliers and customers;

- universities and public research and development laboratories, their ability to create general knowledge realising the educational mission and catering for the demand of the business sector;

- economic policy oriented towards education of the labour force, creating pro-development climate in the macroeconomic financial and trading system, and strengthening the trust in financial institutions and the rule of law. 
The dynamics of this system can be explained by the growing role of science in the economy: the so-called 'science push effect'. Higher education is a factor which integrates the educational and universal capacity of science, leading to economic growth, mainly through social and institutional change. The structure of the components and factors of an innovation system can assume the form of technical infrastructure comprised of:

- competitive and co-operative capabilities of enterprises: in both horizontal and vertical configurations (including $R \& D$, distribution and purchasers), as well as in regional, national and international configurations;

- academic and public research and development laboratories with their opportunities to co-operate with foreign academic institutions, national and local political spheres, as well as with the industrial sector and other social institutions;

- the government with its, internal and foreign, scientific, educational, and social policies aimed at improving competitiveness, being a direct consequence of the functioning of the economy and controlled by public institutions.

Analysis of regional innovation systems aims to indicate their innovative potential and identify the ways to enhance it. This concerns both the innovation activity of enterprises and the institutional forms of providing support for these activities.

Regional innovation systems (RIS) evolve like any other system. Thanks to current, dynamic signals from the market, it is possible to spot the changes and pinpoint their exact nature. RISs often depart from the traditional structural construction for the sake of new forms of obtaining knowledge and information. The traditional 'one best way' approach, dating back to Fordism, saw innovation as a hierarchical process based on knowledge production centres, which passed knowledge on to subordinate contractors. Nowadays, it is rather a network system: a web of mutual relationships between several independent groups.

Every enterprise is a collection of so-called routines: rules, not always formal, which have been adopted to streamline production processes. Innovation, meanwhile, is a sequential process, based on the application of abstract knowledge. RISs, which possess significant capacities to evolve, enable the creation of a complex system for transforming knowledge: from the moment it comes into being to the moment it is applied in the broadest possible way.

The nature of the processes of knowledge application in a region is such that they should undergo evolutionary, and not revolutionary, changes. Besides, these changes should be associated with market processes, focused on the creation and application of knowledge. 
The evolutionary approach to RISs helps explain numerous processes that take place inside them, e.g. the creation of knowledge in enterprises, knowledge transfer, or the dynamics of change in human capital.

Regional innovation policies can also be implemented through so-called milieux innovateurs. ${ }^{2}$ Under certain circumstances a region can become such a milieu. First of all, there must be geographical proximity of small and medium enterprises, social and institutional networks, mutual relationships of interdependency and trust, as well as transferred (informal and contextrelated) knowledge. Knowledge spreads through: (i) the relationships of customers and purchasers with producers and users of production means, enterprises, employees, and (ii) setting up new companies (Salmi et al., 2001, p. 20). A 'milieu' is, therefore, a new type of relationship between enterprises and institutions (Maillat, 1996, p. 13).

The RIS model is under constant influence of structural change or current trends in the global economy, as well as of a number of endogenous factors. Unstable external environment and the fierce competition from other regions make it necessary to continually come up with fresh innovations in order to strengthen the competitive position. What could be of tremendous help are new competition strategies based on knowledge.

Enterprises which operate within RISs can obtain knowledge in two ways: by individual learning or by interaction with other firms. Individual learning includes (OECD, 1996):

- learning-by-doing: improving efficiency through repeatability of processes;

- learning-by-using: improving efficiency thanks to better systems of production or management;

- learning-by-interacting: co-operation of, e.g., producers and purchasers towards streamlining products;

- learning-by-learning: a firm's ability to absorb innovation is dependent on prior learning experience.

An interactive process, on the other hand, involves learning by exchange of information with other local entities. Enterprises located in close vicinity to one another maintain more frequent contacts, which stimulates new forms of co-operation for knowledge acquisition and creation. As a result, innovations induced by new knowledge come into being (Arrow's model) (Arrow, 1962).

Arrow's conception originates from experimental psychology, which assumes that all kinds of learning ensue from experience that is not a function of time, but of practice and active involvement. The categories of 'learning

\footnotetext{
${ }^{2}$ The local nature of a milieu is an equivalent of Marshall's industrial atmosphere. The term was first used in the GREMI (Groupe de Recherche Europeen sur les Milieux Innovateurs) project for studying the differences in regional development.
} 
curve' and 'experience curve' can be used to describe the model of business activity. Arrow proposes that the pace of innovation and the current level of knowledge are a consequence of production experience. Innovation is embodied in new capital equipment funded from investments, and can be found in capital goods sectors. By combining the experience of the capital sector and the efficiency of the staff that operate new machinery and equipment. innovation leads to an increase in the efficiency of labour (Arrow, 1962, p. 170).

Arrow's model is an attempt at an endogenisation of the idea of innovation. It describes how the labour input necessary for manufacturing a product gradually decreases along with the growth of knowledge and experience. Moreover, it points out that increasing returns to scale are inherent in innovation.

The above approach to induced innovation demonstrates how R\&D expenditure is realised. Enterprises choose such types of innovation which differ in terms of the intensity of production factor utilisation. Relative changes in the prices of production factors show which innovation projects can be implemented so as to achieve the cost reduction criterion. Projects which are optimal as regards the factor prices can prove undesirable when other aspects are taken into account, e.g., increased salaries (Uzawa, 1965, p. 22).

Innovation is limited by the amount of accessible scientific and technological knowledge, decreasing due to falling revenue from $R \& D$. Therefore, innovators are facing important decisions concerning (Coombs et al., 1987, p. 108):

- reduction of production costs;

- increasing the complexity of innovation processes;

- choosing which innovation projects can be implemented within the limits of accessible knowledge.

This means that the cost of production factors is not always the only consideration when it comes to selecting an innovation strategy. A similar approach is proposed by Binswanger, who distinguishes three innovation factors: profits from innovation, costs of innovation and the limits of technical possibilities. He describes a positive relationship between the volume of production and the level of $R \& D$ expenditure, pointing out the dependence among current prices of production factors, $R \& D$ structure (labour-saving or capital-saving) and the change in time of the innovation curve (Binswanger, 1974, pp. 953-956). Since he treats R\&D expenditure as a normal investment, research projects are dependent on production factors, research productivity and expected costs. A selection process based on these criteria determines the direction and dynamics of innovation. 
Social learning consists mainly in the relationships that enterprises establish with other entities. They can assume various forms: (i) the relationships among companies (co-operation, competition, supplies); (ii) the relationships between firms and institutions (co-operation, dependence), and (iii) the relationships between enterprises and individual creators of knowledge (information, co-operation).

Learning-by-location means taking advantage of Marshall's external effects. It allows small companies to jointly exploit knowledge, and attracts transnational enterprises to a region as the latter usually seek common resources generated by clusters of firms, instead of resources owned by individual companies. Local systems draw from the external environments, adapting innovative solutions implemented in global markets.

Creation (new uses) of knowledge depends, moreover, on such characteristics of a company as learning capability and absorption of new knowledge. Meanwhile, knowledge itself is spread within a region via employees, regional relationships and imitation. The background of regional market makes intellectual connections between enterprises possible. The differences in learning are also determined by regional specialisation and local division of labour.

RISs consist of two subsystems (Autio, 1998, pp. 131-140). The subsystem of application and exploitation of knowledge encompasses firms, their customers, suppliers, competitors and collaborators (often functioning in clusters). The enterprises are connected by vertical and horizontal linkages. The other subsystem is one of creation and diffusion of knowledge. It is comprised of a number of educational institutions (universities, learning centres) and research institutions (innovation centres, technology transfer units, patent offices etc.) which play an intermediary role in providing technologies and personnel.

A major role is also played by political institutions, which shape the innovation processes in a given region by providing operating procedures and financial resources, and by creating regional innovation policy. In a properly functioning RIS, all these entities form a network of dependencies and interactions regarding the flow of knowledge, resources and qualifications.

All these interrelations are tremendously important for the innovation potential and competitive position of RISs. Internal connections concerning knowledge flows are believed to be of great significance in innovative regions, but interactions with external bodies as regards support for the development of knowledge seem no less relevant.

Formal networks require some sort of financial (or material) compensation, whereas informal ones occur spontaneously and are free of charge. Static relations, on the other hand, involve exchange of "ready-made" frag- 
ments of knowledge or information, and are dynamically associated with the activities aimed at learning-by-interacting.

The capacity for increasing knowledge, and the extent to which this resource is used, depend on the degree of integration between the particular parts of an RIS, as well as the strength of the ties discussed above.

Table 1. Types of linkages to external knowledge sources and partners

\begin{tabular}{|c|c|c|}
\hline & Static (knowledge transfer) & $\begin{array}{c}\text { Dynamic } \\
\text { (collective learning) }\end{array}$ \\
\hline $\begin{array}{l}\text { Formal/traded } \\
\text { relations }\end{array}$ & $\begin{array}{l}\text { Market relations } \\
\text { - contract research } \\
\text { - consulting } \\
\text { - licences } \\
\text { - buying of intermediate goods }\end{array}$ & $\begin{array}{l}\text { Formal netoworks } \\
\text { - R\&D cooperations } \\
\text { - shared use of } R \& D \text { facilities }\end{array}$ \\
\hline $\begin{array}{l}\text { Informal/untraded } \\
\text { relation }\end{array}$ & $\begin{array}{l}\text { Spillovers } \\
\text { - mobility of specialists } \\
\text { - monitoring of competitors } \\
\text { - participation in fairs, confer- } \\
\text { ences } \\
\text { - reading of scientific literature, } \\
\text { patent specification }\end{array}$ & $\begin{array}{l}\text { Informal networks } \\
\text { - informal contacts } \\
\text { - social events } \\
\text { - internet chatrooms } \\
\text { - virtual knowledge communi- } \\
\text { ties }\end{array}$ \\
\hline
\end{tabular}

Source: Todtling, Trippl (2011, p. 459).

A number of data indicate (Maskell et al., 2006, pp. 997-1008) that enterprises which belong to such networks gain access to knowledge (both codified and context-related) and information from increasingly varied sources. Besides, the co-operation between knowledge makers and knowledge users is becoming far wider and more intensive.

\section{Determinant factors of innovation potential of Podlaskie Voivodeship}

In 2010, Podlaskie Voivodeship's capital expenditure on R\&D was only slightly more than $1 \%$ of such expenditure in Poland. In comparison to other Polish provinces, this was one of the lowest indicators $\left(14^{\text {th }}\right.$ place $)$. In that year, R\&D activity was conducted in 52 entities in Podlaskie, 21 of which were business companies. This ranked the Voivodeship 13th in Poland (Foresight..., 2012, p. 57).

In 2009, the overall amount of capital investment per one employed person in Podlaskie was merely $74 \%$ of the national average, which ranked the region in the penultimate position in Poland (see Figure 1). In earlier years, 
there had been a growing trend in R\&D spending, but 2009 brought a decrease in the indicator. This was due to the fact that research activity of enterprises had been limited and science centres had restricted their expenditure on primary research.

Figure 1. Investment expenditures per capita (PLN, 2009)

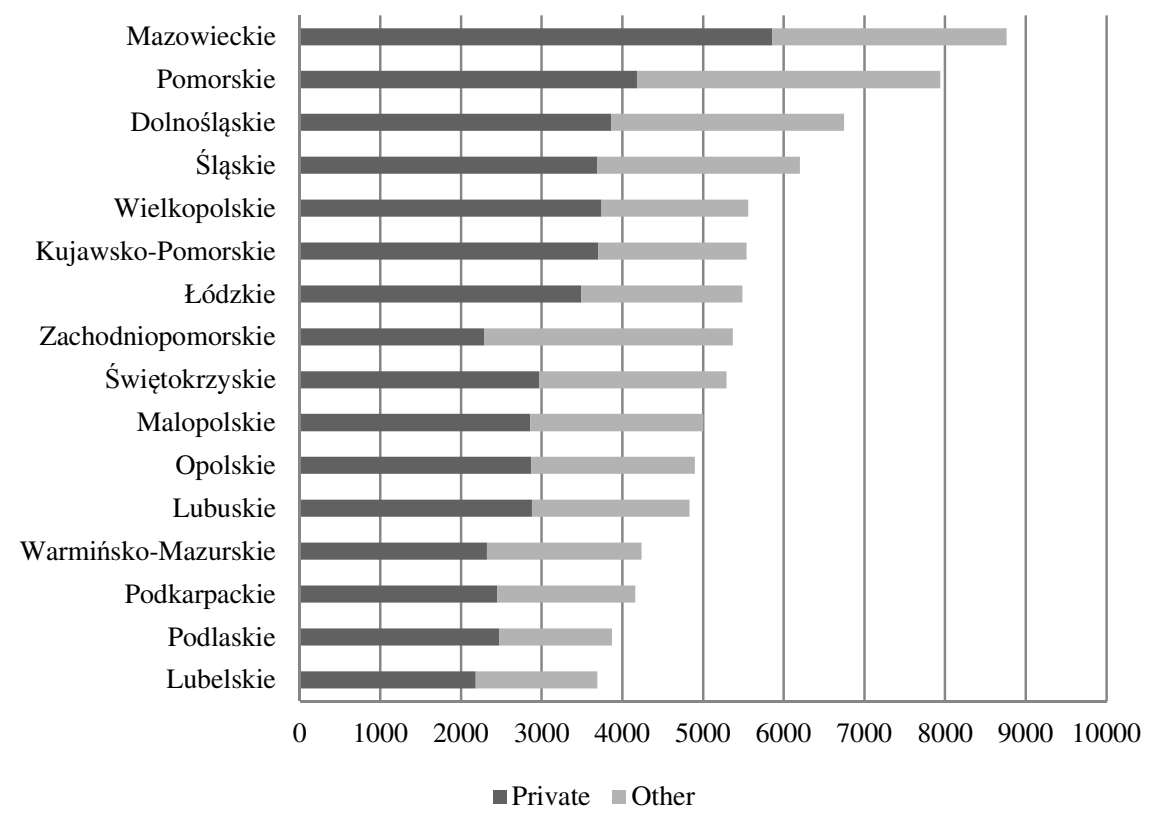

Source: Bank Danych Lokalnych, www.stat.gov.pl, (15.03.2011).

Another reason for the weakness of Podlaskie's firms is the structure of innovation funding. Nearly $50 \%$ of the region's enterprises use mainly their own resources, $15 \%$ use bank credits, $6.2 \%$ - foreign funding, $2.6 \%$ - state budget funding, and merely $1.4 \%$ finance innovation from venture capital. Bearing in mind that only a fraction of firms generate high income, it is clear that the innovation capacity of the regional business sector is seriously impaired.

For a peripheral region like Podlaskie, public funding could become a significant source of investment in innovation. And yet, a mere $10 \%$ of local companies have received financial support in this respect. Additionally, most of the funding was obtained by large and profitable firms, which confirms the fact that small and medium enterprises are seriously disadvantaged. 
In recent years, innovation indicators have shown an increasing trend. As a result the voivodeship's rankings are highly variable. The greatest improvement was noted in R\&D expenditure per one inhabitant. In 2003, it was merely PLN 32 per inhabitant, while in 2009 it reached PLN 55.7, which meant a $74 \%$ rise, still, however, leaving Podlaskie in the $15^{\text {th }}$ position out of the 17 Polish provinces. In Podlaskie, only 22 entities conduct research and development activity. This is a very low number. In Mazowieckie (the national leader), there are 16 times as many such institutions (Foresight regionalny, 2012, p. 61).

The enterprises sector has the largest share in Poland's R\&D spending structure. In Podlaskie, meanwhile, it is the higher education sector which occupies the leading position in this field, providing employment to nearly $90 \%$ of those involved in research and development in the voivodeship (see Figure 2).

Figure 2. Structure of R\&D expenditures (by sectors, 2009, \%)

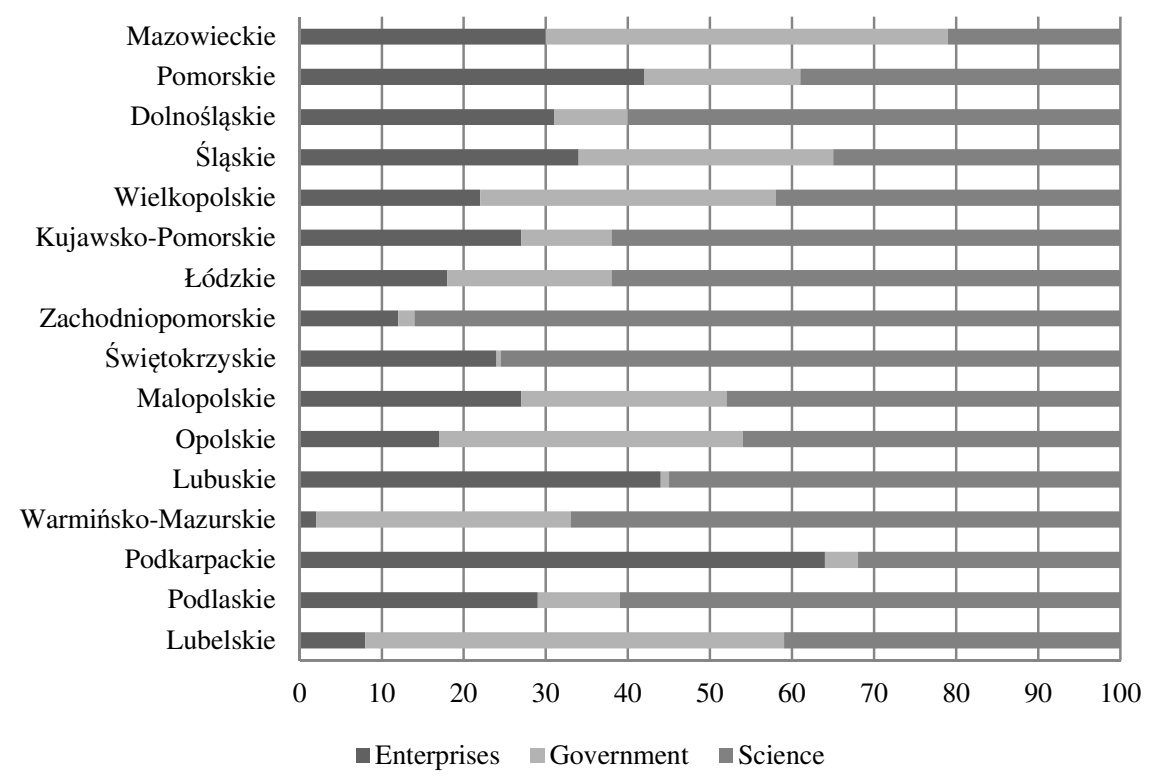

Source: Bank Danych Lokalnych, www.stat.gov.pl, (15.03.2012).

As far as Podlaskie's service sector companies are concerned, the expenditure on innovation per inhabitant is PLN 9. In the industrial sector this figure amounts to PLN 245. In terms of innovation expenditure in industrial 
enterprises, Podlaskie is ranked in the $12^{\text {th }}$ place. The province is ranked in a fairly high $7^{\text {th }}$ spot in the category of net income from the sales of innovation products in the private sector. Here, a $23 \%$ rise has been reported, reaching an $11 \%$ share in net income (see Figure 3).

Figure 3. R\&D expenditures as a \% GDP $(2009, \%)$

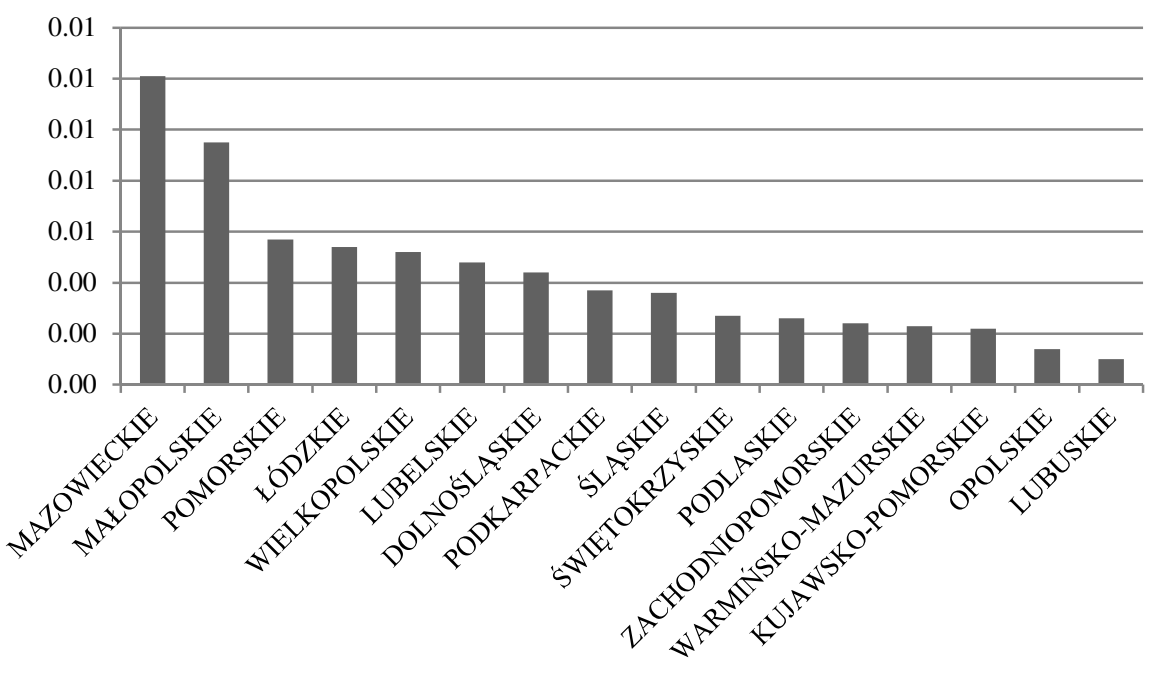

Source: Bank Danych Lokalnych, www.stat.gov.pl (15.03. 2012).

Enterprises can be divided into those whose commitment to innovation is manifested in new or improved products, new or significantly improved products, or new or significantly improved processes. The domestic average percentage of innovative companies is $12.57 \%$ of the firms in the service sector, and $18.10 \%$ in the industrial sector. In Podlaskie, the number of industrial sector companies equals $80 \%$ of the national average. As regards the service sector firms, the situation is even worse, since they account for just $16 \%$ of the national average (see Table 2 ). 
Table 2. Innovation firms (Poland $=100,2009$ )

\begin{tabular}{|l|c|c|}
\hline \multirow{2}{*}{\multicolumn{1}{|c|}{ Voivodships }} & Industry & services \\
\cline { 2 - 3 } & \multicolumn{2}{|c|}{ in \% } \\
\hline dolnośląskie & 116 & 98 \\
\hline kujawsko-pomorskie & 15 & 111 \\
\hline lubelskie & 120 & 103 \\
\hline lubuskie & 13 & 66 \\
\hline łódzkie & 107 & 72 \\
\hline małopolskie & 18 & 103 \\
\hline mazowieckie & 90 & 144 \\
\hline opolskie & 19 & 158 \\
\hline podkarpackie & 120 & 77 \\
\hline podlaskie & 16 & 80 \\
\hline pomorskie & 125 & 86 \\
\hline śląskie & 17 & 123 \\
\hline świętokrzyskie & 99 & 40 \\
\hline warmińsko-mazurskie & 18 & 98 \\
\hline wielkopolskie & 89 & 121 \\
\hline zachodniopomorskie & 19 & 118 \\
\hline
\end{tabular}

Source: Bank Danych Lokalnych, www.stat.gov.pl (15.03.2012).

In Podlaskie Voivodeship, 19\% of industrial enterprises introduce innovative products or processes. This respectable figure ranks the province as high as $6^{\text {th }}$ in Poland. Most frequently, innovation is used for new or significantly improved products, or new or significantly improved processes. In the ranking of service sector firms, Podlaskie occupies $12^{\text {th }}$ place, with $10 \%$ of innovative companies. Innovation usually occurs in new or significantly improved processes.

Similarly to other Polish provinces, Podlaskie's companies make sparse use of either domestic or foreign scientific and technological solutions. On the national scale, firms were slightly more willing to purchase new technologies from domestic partners. One exception being the production automation systems, which tended to be purchased abroad. A similar trend could be observed in Podlaskie. Apart from the systems for production automation, the region's firms frequently resorted to 'other' types of technology transfer from foreign countries. 
Unfortunately, given the meagre involvement in technology transfer in Poland, one cannot help noticing that the business enterprises located in Podlaskie are even less interested in new technological solutions. The only exception was the purchase of production automation systems and 'other forms' of technology transfer.

Even fewer firms in the region (and likewise in the entire country) engaged in the sales of new technologies. The low technological level of Podlaskie's companies is particularly striking in this category: in 2010, only a few firms sold technology in the form of production automation systems to Polish purchasers, and one firm sold such technology to a foreign buyer.

Foreign direct investment was the most common form of obtaining technological solutions from abroad. Several small companies and one large firm used this form of transfer. One large enterprise signed a license agreement concerning technology transfer.

Three medium-sized firms and one large company took advantage of other types of co-operation (joint-venture or memorandum of agreement) to acquire foreign technologies. None of the studied companies signed a franchise agreement. This can be due to the high cost of foreign technological solutions and insufficient commitment to attracting foreign investors.

In Poland, the lower the number of employees a firm has, the less own resources it invests in innovation. Instead of own resources, bank credits are used. In Podlaskie, meanwhile, small and large enterprises tended to invest their own resources. As for medium-sized firms, the shares of own funds and resources from bank credits spent on innovation were similar.

Only medium-sized companies of Podlaskie received financial aid from the state budget. Foreign financing for innovation was a rare occurrence in the voivodeship: only $0.01 \%$ of the expenditure. This is analogous to capital investments overall. The above data reveal the poor financial condition of Podlaskie's business companies, and the virtual absence of foreign capital in the region.

Although the number of firms conducting R\&D activity is relatively low, it should be considered a positive tendency that their level (though only claimed) of innovation is higher than the national average. Data confirm the popular knowledge of poor innovation performance of small and medium enterprises, as opposed to large firms. In Podlaskie, innovation was implemented by $13 \%$ of the small firms, $28.7 \%$ of the medium-sized ones, and $62.5 \%$ of the large ones (Foresight..., 2012, p. 64).

The firms of Podlaskie far less frequently undertake co-operation for innovation than an average Polish company. One exception is co-operation with Polish customers, suppliers of equipment, materials, components, or software, as well as with other firms. When it comes to innovation, the enterprises in the region prefer domestic rather than international co-operation. 
Podlaskie's firms do not co-operate with foreign higher education institutions, consulting firms, customers or competitors. What is important, there is a tendency for the formation of groups of co-operating companies in the agricultural and food processing sector (dairy plants and milk suppliers networks). However, this new type of networks cannot be regarded as fullyfledged clusters.

Podlaskie's companies only to a limited extent take advantage of the region's transboundary location and the resultant co-operation opportunities. Enterprises which sign agreements on co-operation for innovative activity create technological development prospects, and largely contribute to the growth potential of their region, its competitive position, and the evolution of consumer goods markets.

Together, research and development, technology transfer and cooperation for innovation, make up a set of factors which determine innovation performance. Moreover, the transfer of technology and co-operation for innovation can be, in a sense, considered substitutes for R\&D. This means that research and development activity is not always necessary for innovation. Those responsible for the innovation policy of a country or region should bear this in mind, given the low involvement in R\&D of the firms in Podlaskie. In comparison to own research and development initiatives, the transfer of technology and co-operation for innovation might prove a less costly option of obtaining new technological solutions.

A large proportion of the innovating firms in Podlaskie neither purchase technologies nor establish co-operation for innovation, nor undertake R\&D activity. This might mean that many of the new or improved products and processes launched by Polish firms did not have any elements of technological innovation. Acquisition of elements or complete new technological solutions is also a time-saving strategy. The saved time could be used for streamlining the existing technologies rather than for attempting to catch-up with the current technological frontier, basing only on the firms' own resources.

The region would benefit greatly if its firms could overcome this introverted tendency. More involvement in technology transfer and co-operation for innovation (especially with foreign firms and R\&D centres in Poland and abroad) should be strongly supported by the creators of the regional innovation policies since it can help to enhance the innovation level of Podlaskie's companies, thus accelerating the development rate of the region. 


\section{Conclusions}

Podlaskie Voivodeship is in dire need of more dynamic co-operation among the business sector, R\&D sector and self-government institutions. So far the involvement in co-operation for innovation of $R \& D$ centres, e.g. universities, and enterprises has been relatively limited. Entrepreneurs put forward suggestions for establishing closer collaboration between the business and science sectors. The higher education institutions in the region show little flexibility towards market demand, both in terms of programmes of study and research services offered to external customers. According to entrepreneurs, their attempts to start co-operation with the regional universities ended in failure due to the excessive waiting time for study results, unacceptable from the point of view of today's fast-changing business environment.

In Podlaskie, one can also observe relatively little technology transfer, particularly as regards the so-called inward technology transfer, i.e. purchase of new technological solutions. It should be noted that firms from the lowand medium-low-technology sectors are the most active in this respect. The low technology level of Podlaskie's firms is also confirmed by data on outward technology transfer - selling of new technologies.

Taking into account the innovation performance of Podlaskie's enterprises, as well as their engagement in $\mathrm{R} \& \mathrm{D}$, technology transfer and cooperation for innovation, one can notice that they seem to reject technologies created outside, preferring instead to develop new solutions in their own laboratories. As a result, they forfeit the benefits that could be obtained from buying new technology from external firms, which is often cheaper than investing in internal technologies. This is extremely significant considering the fact that the majority of Polish firms struggle with inadequate funding for innovation.

It is, however, also possible to observe certain positive phenomena. The claimed high level of innovation, though not confirmed by the number of patented inventions, is reflected in the structure of income from sales. The value of new and modernised products sold by the region's firms accounts for more than $20 \%$ of the total sales revenue. This means that the products manufactured in our voivodeship are increasingly 'updated', which is very important for competitiveness.

There is also a growing awareness among the entrepreneurs of the necessity to show greater commitment to innovation. This finds a reflection in the dynamically increasing rate of employment in the R\&D sector (partly caused by a rise in the number of university staff in the region), the growing value of scientific equipment, and the amount of money spent on innovation. 
Besides, Podlaskie's business companies are more willing than an average Polish firm to establish co-operation with domestic customers, suppliers and other firms. In a free market economy, entrepreneurs must make certain that they properly cater for the needs of their customers, and this cannot be achieved without close co-operation.

\section{References}

Arrow J.K. (1962), The Economic Implications of Learning by Doing, „Review of Economic Studies", Vol. 29, No. 3, http://dx.doi.org/10.2307/2295952.

Autio E. (1998), Evaluation of RTD in regional systems of innovation, European Planning Studies, 6, No. 2, http://dx.doi.org/10.1080/09654319808720451.

Bank Danych Lokalnych, www.stat.gov.pl, (15.03.2012)

Binswanger H.B. (1974), A Microeconomic Approach to Induced Innovation, „Economic Journal", Vol. 84, No. 336, http://dx.doi.org/10.2307/2230575.

Cooke P., De Laurentis C., Todtling F., Trippl M. (2007), Regional Knowledge Economies, Edward Elgar.

Coombs R., Saviotti P., Walsh V. (1987), Economics and Technical Change, Macmillan, London.

Foresight regionalny (2012), Województwo podlaskie 2020 plus, UWB Białystok.

Maillat D. (1996), From the industrial district to the innovative milleu: contribution to an analysis of territorialized productive organizations, University de Neuchate, Working Paper 1996, nr. 06., Switzerland.

Maskell P., Bathelt H., Malmberg A. (2006), Building global knowledge pipelines: the role of temporary clusters, "European Planning Studies", Vol. 14, No. 8, http://dx.doi.org/10.1080/09654310600852332.

North C.D. (1997), The Process of Economic Change, „Wider Working Papers”, No. 128, Helsinki.

OECD (1996), The Knowledge-Based Economy, Paris

Salmi P., Blomqvist K., Ahola J., Kylaheiko K. (2001), Industrial districts and regional development, Towards a knowledge based view, Lappeenranta University of Technology, Finland.

Todtling F., Lehner P., Trippl M. (2006), Innovation and knowledge intensive industries: the nature and geography of knowledge links, European Planning Studies, Vol. 14, No. 8, http://dx.doi.org/10.1080/09654310600852365.

Todtling F., Trippl M. (2011), Regional innovation systems [in:] Cooke P., Handbook of Regional Innovation and Growth, Edward Elgar.

Uzawa H. (1965), Optimum Technical Change in an Aggregative Model of Economic Growth, "International Economic Review", Vol. 6. 